Nadas, A. S. and Fyler, D. C. (1972). Pediatric Cardiology, p. 597. W. B. Saunders, Philadelphia and London.

Nora, J. J. (1968). Multifactorial inheritance hypothesis for the etiology of congenital heart diseases. The genetic environmental interaction. Circulation, 38, 604-617.

Nora, J. J., McGill, C. H., and MacNamara, D. G. (1970). Recurrence risks in common and uncommon congenital heart lesions. Teratology, 3, 325-330.

Nora, J. J., MacNamara, D. G., and Fraser, F. C. (1967). Hereditary factors in atrial septal defect. Circulation, 35, 448-456.

Simcha, A. and Bonham-Carter, R. E. (1971). Ebstein's anomaly Clinical study of 32 patients in childhood. British Heart fournal, 33, 46-49.

Streeter, G. L. (1951). Developmental Horizons in Human Embryons Age Groups XI-XXIII. Carnegie Institution of Washington, Washington D.C.

Watson, H. (1974). Natural history of Ebstein's anomaly of tricuspid valve in childhood and adolescence. An international cooperative study of 505 cases. British Heart fournal, 36, 417-427.

Zetterqvist, P. (1971). Accumulation of different congenital heart defects in one pedigree. Clinical Genetics, 2, 123-127.

\section{Partial trisomy D: a diagnostic and cytogenetic dilemma*}

\author{
Summary. An 18-month-old pro- \\ posita with psychomotor retardation and \\ other congenital abnormalities is pre- \\ sented. Chromosomal analysis of both \\ parents proved normal. However, the \\ karyotype of the proposita contained 47 \\ chromosomes in both lymphocytes and \\ cultured fibroblasts. The marker chro- \\ mosome proved to be a deleted No. 14 or \\ 15. Comparison of the reported cases of \\ partial trisomy $\mathrm{D}$ indicates that a defini- \\ tive clinical syndrome is not apparent in \\ either case.
}

With the institution of chromosome banding techniques, many new 'partial trisomy' syndromes have been identified (Lewandowski and Yunis, 1975). The majority of these cases result from clinically abnormal, chromosomally unbalanced segregants of reciprocal translocations. Therefore, karyotypic analysis allows the identification of the additional chromosomal material so that phenotypic-karyotypic correlations are possible. However, other instances of partial trisomy are the result of nondisjunction of apparently deleted chromosomes, leading to an extra abnormal marker chromosome.

* Supported in part by a grant from The National FoundationMarch of Dimes.
We wish to describe a child with psychomotor retardation and congenital anomalies possessing 47 chromosomes with partial trisomy ' $D$ '. Banding revealed that the marker chromosome was definitely not a No. 13 and its assignment to either No. 14 or 15 was difficult.

\section{Case report and family history}

The proposita is the only child of healthy, unrelated parents, the mother being 26 years old and the father 27 . The mother had had one previous miscarriage. During the present pregnancy, she received hormone therapy because of vaginal bleeding in the second month. The proposita was born at term after a normal delivery and weighed $2700 \mathrm{~g}$. Bilateral congenital dislocation of the hip was diagnosed shortly after birth.

The baby was referred to the Department of Human Genetics at 18 months of age because of psychomotor retardation, generalized hypotonia, seizures during the last two months, and additional congenital anomalies. On physical examination a left epicanthal fold and divergent strabismus of the right eye were observed (Fig. 1a). The ears were small with very small antehelices. Scars from the removal of preauricular skin tags were evident. The nares were anteverted; the palate was high and arched. A low hair line was observed on a short neck. A large cavernous haemangioma was present on the right forearm (Fig. 1b). The fingers and toes seemed short and somewhat large. Hypotonia was pronounced and head lag was present. Fundoscopy, audiometry, electroencephalogram, $x$-rays of skull and chest, and bone age, as well as haematological examination and urinary screening tests for mucopolysaccharidosis and amino acids were all within normal limits.

\section{Cytogenetic studies}

Chromosomes, from phytohaemagglutinin (PHA) stimulated peripheral lymphocytes, were studied in the proposita and her parents. In addition, cultured skin fibroblasts of the proposita were examined. The initiation, culture, and harvest of cells for cytogenetic evaluation were according to standard methods. G-banding patterns were achieved by the 'hot-plate Giemsa $p \mathrm{H} 9$ ' technique of Patil et al (1971).

The karyotypes of the parents were numerically and structurally normal. In both lymphocytes and fibroblasts, the proposita had a modal chromosome number of 47 with an extra small acrocentric chromosome, the same size and morphology as a G group element. This marker participated in satellite association with other acrocentrics in $40 \%$ of the metaphases. After G-banding (Fig. 2), it became apparent that the marker was not a member of Group G, but did fit the pattern of either a deleted No. 14 or 15. However, without the presence of the distal portion of the long arm. allowing distinction between these two chromosomes, precise identification of the marker was difficult. None the less, based on the proximity to the centromere and size of the proximal darkly staining wide band (14q21), we felt that this 


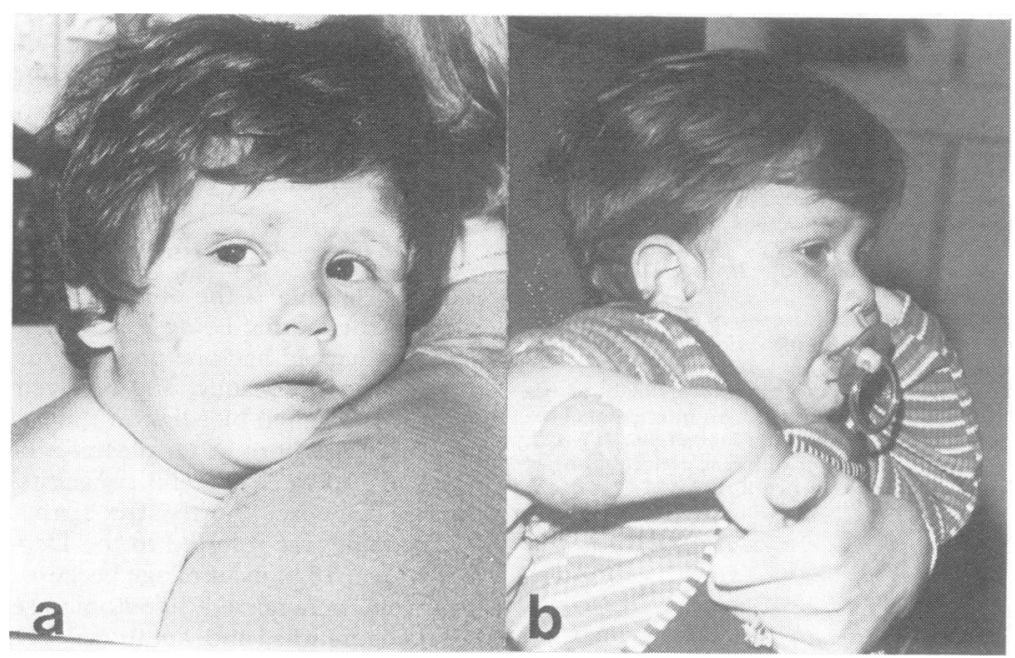

Fig. 1. The proposita: (a) note right divergent strabismus and left epicanthal fold; (b) note preauricular skin tag and cavernous haemangioma.
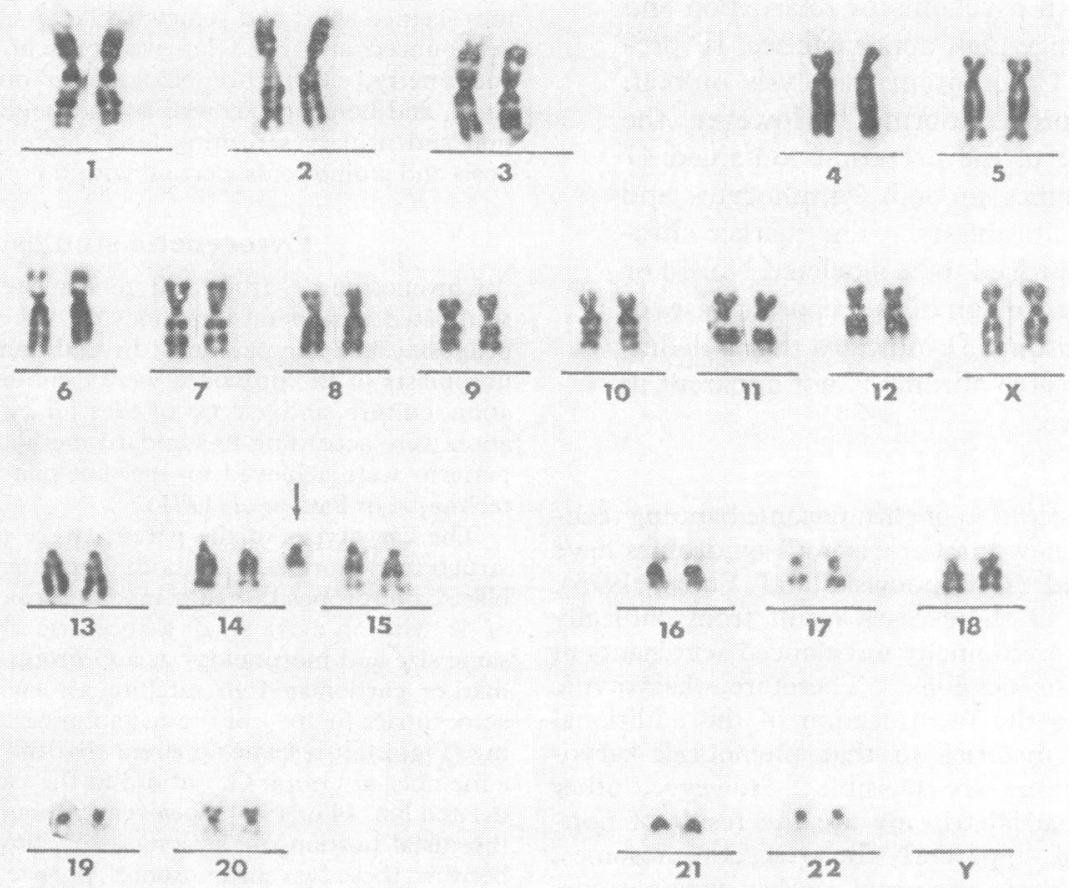

FIG. 2. G-banded karyotype of the proposita. Arrow indicates extra 'G' group-like marker which is a partial No. 14. 
marker was more likely to be a segment of chromosome No. 14 with the break point in the light band $14 \mathrm{q} 22$. If this interpretation is correct, the patient is partially trisomic for the majority of chromosome No. 14 .

\section{Discussion}

Even among patients with identical complete autosomal trisomy syndromes, phenotypic variability sometimes exists. Such variability is much more pronounced in cases of partial trisomy. This problem is readily understood by considering the cytological basis for these conditions. All partial trisomies are predicated upon chromosomal breaks which may result in either translocations or deletions. Since all break points will not be identical, the resultant chromosomal imbalance will differ from patient to patient. Consequently, the phenotype of different partial trisomies involving the same chromosome may be highly variable. However, if the chromosome in question cannot be precisely identified and may, in fact, represent a segment of one of several chromosomes, the basis for clinical variability is considerably broadened.

Among the 8 cases of partial trisomy 14 reviewed by Raoul et al (1975), the most consistent clinical findings include psychomotor as well as growth retardation and microphthalmia. Other malformations such as microcephalus, ptosis, high arched or cleft palate, a peculiarly shaped mouth, prominent nose, low set ears, congenital heart disease, and different limb anomalies were observed in variable proportions of the patients. Of these cases, 7 resulted from translocation malsegregation and one (Muldal et al, 1973) was sporadic, as in the presently reported case.

Eight cases of partial trisomy 15, yielding chromosomal markers similar to that observed in our case, have been reported (Cohen et al, 1975; Crandall et al, 1973; Magenis et al, 1972; Parker and Alfi, 1972; Rethoré et al, 1973; Webb et al, 1971). The only constant feature was moderate to severe mental retardation. Other variable findings included strabismus, antimongoloid slant, seizures, hypotonia, hyperactivity, and skeletal deformities. Most authors felt that these signs were not specific enough to constitute a well-delineated clinical syndrome. An additional case, partially trisomic for the distal portion of $15 \mathrm{q}$ (Fujimoto et al, 1974) manifested psychomotor retardation, microcephalus, seizures, cataracts, low set ears, micrognathia, hearing defect, and long tapering fingers. This phenotype differs somewhat from those patients with partial trisomy for the proximal part of 15q.

The cytogenetic evolution of this type of aberration involves at least two events: one, leading to the inclusion of the extra marker chromosome, i.e. nondisjunction, and the second giving rise to loss of the distal segment of the long arm of the marker, i.e. deletion. In most cases, the apparent deletion occurs as an integral part of a translocation, with the missing segment located on another chromosome. In a minority of cases a direct loss of chromatin material seems to have occurred. Since in our family both parental karyotypes were normal, with no evidence of translocation, a deletion seems most feasible. Furthermore, since mosaicism was not observed in either tissue examined, it may be further assumed that nondisjunction of the deleted marker occurred before fertilization, yielding an unbalanced parental gamete, which included the marker chromosome. In neither partial trisomy D-syndrome (14 or 15), yielding extra G-like marker chromosomes, does a definite clinical basis exist upon which a firm diagnosis can be made. The cytogenetic classification of these markers may also be difficult if the banding is any less than optimum. The patient described here had several clinical features compatible with the reported cases of partial trisomy 14, though the fit was by no means complete. No similarity at all exists between our case and those of partial trisomy 15 . Therefore, it is only through the collection of a large number of cases which are described in detail, both clinically and cytogenetically, that answers to the diagnostic dilemma presented by such patients may be forthcoming.

\section{Maimon M. Cohen, Ada Rosenmann, Judith DAGAN, and CYRIL LEGUM}

The Department of Human Genetics, The Hadassah-Hebrew University Medical Center, Ferusalem; and Genetics Department, Rokach Hospital, Tel-Aviv, Israel

\section{REFERENCES}

Cohen, M. M., Ornoy, A., Rosenmann, A., and Kohn, G. (1975). An inherited translocation $[\mathrm{t}(4 ; 15)(\mathrm{p} 16 \mathrm{q} 22)]$ leading to two cases of partial trisomy 15. Annales de Génétique, 18, 99-103.

Crandall, B. F., Muller, H. M., and Bass, H. N. (1973). Partial trisomy of chromosome No. 15 identified by trypsin Giemsa banding. American Fournal of Mental Deficiency, 77, 571-578.

Fujimoto, A., Towner, J. W., Ebbin, A. J., Khalstrom, E. J., and Wilson, M. G. (1974). Inherited partial duplication of chromosome No. 15. Fournal of Medical Genetics, 11, 287-290.

Lewandowski, R. C. and Yunis, J. J. (1975). New chromosomal syndromes. American fournal of Diseases of Children, 129, 515529.

Magenis, R. E., Overton, K. M., Hecht, F., Macfarlance, J. P., and Keiss, J. A. (1972). Partial trisomy 15. Lancet, 2, 1365.

Muldal, S., Enoch, B. A., Ahmed, A., and Harris, R. (1973). Partial trisomy $14 \mathrm{q}-$ and pseudosanthoma elasticum. Clinical Genetics, 4, 480-489.

Parker, E. C. and Alfi, O. S. (1972). Partial trisomy of chromosome 15. Lancet, 1, 1073. 
Patil, S. R., Merrick, S., and Lubs, H. A. (1971). Identification of each human chromosome with a modified Giemsa stain. Science, 173, 821-822.

Raoul, O., Rethoré, M. O., Dutrillaux, B., Michon, L., and Lejeune, J. (1975). Trisomy 14q partielle. I. Trisomie 14 partielle par translocation maternelle $\mathrm{t}(10 ; 14)(\mathrm{p} 15,2 ; \mathrm{q} 22)$. Annales de Génétique, 18, 35-39.

Rethoré, M. O., Dutrillaux, B., and Lejeune, J. (1973). Translocation $46, \mathrm{XX}, \mathrm{t}(15,21)(\mathrm{q} 13 ; \mathrm{q} 22,1)$ chez la mère de deux enfants atteints de trisomie 15 et de monosomie 21 partielles. Annales de Génétique, 16, 271-275.

Webb, G. C., Garson, M., Robson, M. K., and Pitt, D. B. (1971). A partial D-trisomy/normal mosaic female. Fournal of Medical Genetics, 8, 522-527.

\section{Larsen syndrome in two generations of an Italian family}

Summary. This paper describes a familial case of Larsen syndrome. Typical anomalies were present in the propositus and 2 of his 6 daughters. In addition, all patients had progressive deafness and the 2 daughters had cleft palate. The certain exclusion of any consanguinity between the couple, suggests, in this instance, the dominant mode of transmission of the syndrome.

The association of multiple congenital joint dislocations with characteristic facies is known as Larsen syndrome (Larsen, Schottstaedt, and Bost, 1950). The main clinical findings include: flattened face with depressed nasal bridge, anterior dislocation of the tibia, bilateral dislocation of hips and elbows, and deformities of feet and hands. Mental development as well as the result of a number of laboratory studies are normal. To date, more than 20 instances have been reported, some of them having minor variations of the classical picture (Lee, 1973).

We have studied a family from Southern Italy in which 2 children and their father were affected. This is, to our knowledge, the only severe male case known to have transmitted the full syndrome to his children.

\section{Case reports}

The pedigree of the family is shown in Fig. 1. The propositus (III.8) was a 54-year-old man, height $135 \mathrm{~cm}$. He was the last of 4 sibs, the product of a consanguineous mating. None of his sibs had any deformity: however, one member of the kindred was affected by deafness (I.5) and another one by progressive blindness and deafness (III.1). Our patient married a normal woman who certainly could not be consanguineous, because she came from another city, about $400 \mathrm{~km}$ away. They had 6 children, all females, and the last two, 12 years and 7 years of age, respectively, had the same deformities as their father (Fig. 2).

Briefly, they all presented the complete picture of Larsen syndrome: flattened face with hypertelorism, strabismus, antimongoloid palpebral fissures, low set ears, scapho-oxycephaly; bilateral joint dislocations of hips, elbows, knees, and deformities of feet and hands. In addition, there was progressive deafness and cleft palate in the two daughters. Radiological examinations showed the typical congenital joint dislocations of the hips, knees, elbows, as well as abnormalities of the skull (scaphooxycephaly), synostosis of some tarsal bones, and metacarpophalangeal subluxations. Biochemical data and chromosome analyses were normal. Mental development was normal.

\section{Discussion}

Our observations are consistent with a diagnosis of Larsen syndrome: in fact, such diagnosis may be posed whenever there are at least two main features -that is characteristic flattened face and congenital joint dislocation (Silverman, 1972). Though having the full-blown picture, the severity was nevertheless different among the three subjects: while the propositus and his older daughter were able to walk, but with some difficulty, the other daughter who was 7 years old, was unable even to stande This is consistent with the well-known variability of expresssivity of the gene (Latta et al, 1971).

As regards the mode of inheritance of the syndrome, most observations are consistent with auto-

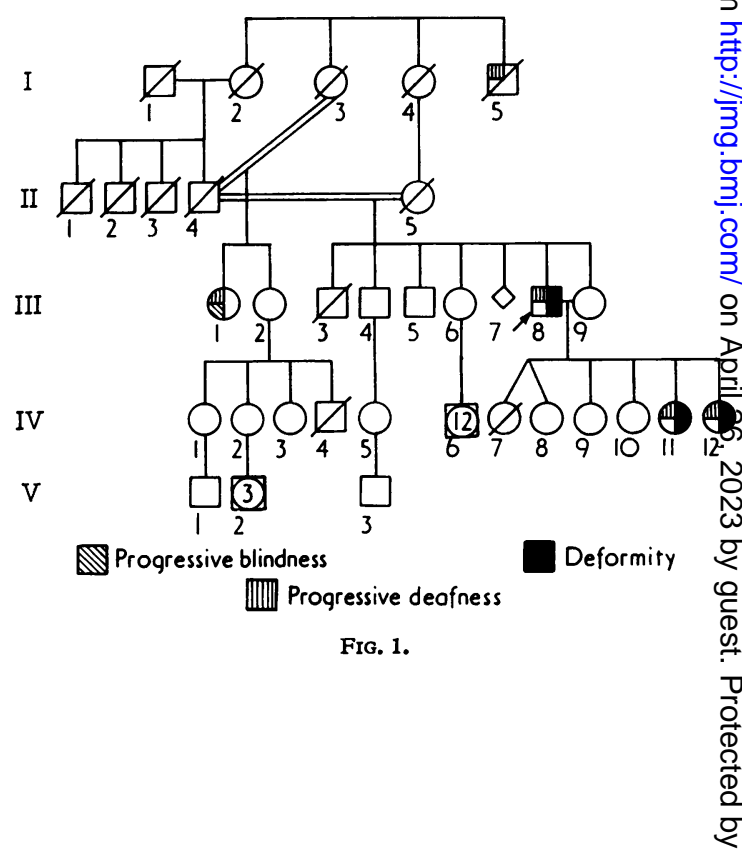

